\section{Phenytoin intoxication during treatment with parenteral miconazole}

We describe a patient in whom phenytoin toxicity developed soon after treatment with parenteral miconazole.

\section{Case report}

A 51 year old man was admitted for treatment of recurrent severe haemoptysis associated with pulmonary aspergillosis. He was in chronic respiratory failure. He was a non-smoker. Biochemical indices of liver function were normal. There was a past history of asthma and also of epilepsy for 20 years, for which he was receiving phenytoin capsules $300 \mathrm{mg}$ daily. The epilepsy was well controlled and the dose of phenytoin had remained unchanged for five years. During this time he had complained of intermittent dizziness and unsteadiness, but the plasma phenytoin concentration had not been estimated.

He began treatment with intravenous miconazole $500 \mathrm{mg}$ every eigh hours and oral flucytosine $2 \mathrm{~g}$ every six hours. The phenytoin dosage and formulation remained unchanged. The next day he complained of nausea, vomiting, and blurred vision and was treated with metoclopramide. Three days later his symptoms were more severe and pronounced nystagmus was noted. These symptoms and signs were attributed to the miconazole and the dose was decreased to $400 \mathrm{mg}$ every eight hours; however, his symptoms persisted.

One week after beginning the antifungal treatment his plasma phenytoin concentration (EMIT, Syva Industries) was found to be $170 \mu \mathrm{mol} / 1(43 \mu \mathrm{g}$ $\mathrm{ml}$ ) (our recommended therapeutic range is $40-80 \mu \mathrm{mol} / 1 ; 10-20 \mu \mathrm{g} / \mathrm{ml}$ ). Phenytoin was stopped for 12 days, during which time the plasma concentration fell to $39 \mu \mathrm{mol} / 1(9.8 \mu \mathrm{g} / \mathrm{ml})$ and his symptoms and signs subsided. During this time miconazole was stopped for four days and then reinstituted (figure).

Phenytoin was restarted at $100 \mathrm{mg} /$ day, and 20 days later the plasma concentration was $91 \mu \mathrm{mol} / 1(23 \mu \mathrm{g} / \mathrm{ml})$. Miconazole and flucytosine were then stopped, and 10 days later the plasma phenytoin concentration had fallen to $57 \mu \mathrm{mol} / 1(14.3 \mu \mathrm{g} / \mathrm{ml})$

When we realised that phenytoin toxicity was the cause of the patient's symptoms, two samples of blood which had been collected and stored for other purposes were analysed retrospectively for phenytoin concentration. The value from the day before beginning miconazole and flucytosine was $114 \mu \mathrm{mol} / 1(29 \mu \mathrm{g} / \mathrm{ml})$ (figure), which, together with his history of intermittent dizziness, suggested that he had had mild phenytoin toxicity before the antifungal treatment.

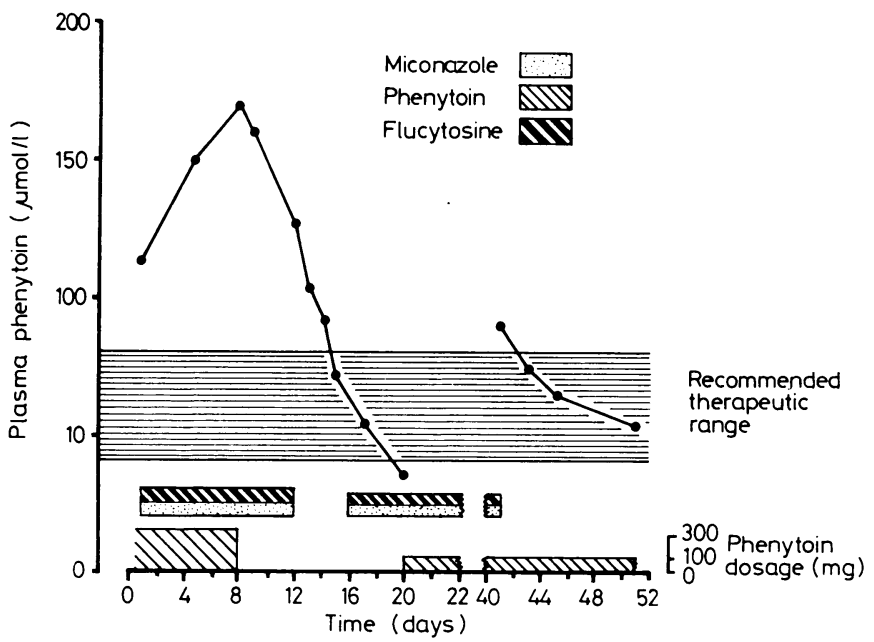

Plasma phenytoin concentrations during antifungal treatment. Dose of miconazole in first treatment period was $500 \mathrm{mg}$ every eight hours, and in second treatment period $400 \mathrm{mg}$ every eight hours. In both treatment periods flucytosine was given by mouth at a dose of $2 \mathrm{~g}$ every six hours.

Conversion: SI to traditional units-Phenytoin: $1 \mu \mathrm{mol} / 1 \approx 0.25 \mu \mathrm{g} / \mathrm{ml}$.

To eliminate spurious increases in EMIT phenytoin concentrations by miconazole or flucytosine these drugs were added, in concentrations up to five times those achieved therapeutically in plasma, to samples containing known concentrations of phenytoin: no effect was found.

\section{Comment}

The most likely mechanism for the increase of phenytoin concentrations was inhibition of phenytoin metabolism by miconazole. \& There are two reasons for this. Firstly, the plasma phenytoin con- T centration fell when antifungal treatment was stopped with no change in phenytoin dosage or formulation. Secondly, miconazole in vitro is a potent inhibitor of the hepatic cytochrome P-450 enzymes, ${ }^{1} \stackrel{\sim}{\rightarrow}$ which are responsible for phenytoin metabolism. Also cimetidine, another imidazole structurally related to miconazole, inhibits phenytoin metabolism in man. ${ }^{23}$

The only drug interaction with miconazole in vivo of which we are aware is potentiation of the effect of warfarin ${ }^{4}$; however, patients receiving parenteral miconazole concurrently with phenytoin or other drugs that are metabolised in the liver should be closely observed.

1 Drew R, Scott J. Interaction of imidazole drugs with hepatic cytochrome P-450 dependent enzymes. Clin Exp Pharmacol Physiol (in press).

${ }^{2}$ Hetzel DJ, Bochner F, Hallpike JF, Shearman JC, Hann CS. Cimetidine interaction with phenytoin. $\mathrm{Br}$ Med $\mathcal{F} 1981 ; \mathbf{2 8 2}: 1512$

${ }^{3}$ Somogyi A, Gugler R. Drug interactions with cimetidine. Clin Pharmacokinet $1982 ; 7: 23-41$.

${ }^{4}$ Watson RG, Locahn RG, Redding VJ. Drug interaction with coumarin derivative anticoagulants. $\mathrm{Br}$ Med F 1982;285:1045-6.

(Accepted 26 August 1983)

Department of Clinical Pharmacology, Royal Adelaide Hospital,

Adelaide, South Australia 5000, Australia

PAUL E ROLAN, MB, BS, clinical pharmacology registra

ANDREW A SOMOGYI, PHD, visiting pharmacologist

MICHAEL J R DREW, MB, FRACP, assistant director, thoracic medical unit

WILLIAM G COBAIN, MB, BS, registrar, thoracic medical unit

DIANA SOUTH, BPHARM, senior pharmacist

FELIX BOCHNER, MD, FRACP, professor of clinical pharmacology

Correspondence to: Dr Paul E Rolan.

\section{Human cryptosporidiosis: a possible case of hospital cross infection}

The protozoan Cryptosporidium causes enterocolitis in animals, ${ }^{12}$ and the importance of cryptosporidiosis in man was recently emphasised. Cases in man are being reported increasingly now that simple methods are available to detect oocysts in faeces. ${ }^{4}$ Severe infections occur in immunocompromised people, including those with acquired immune deficiency syndrome, ${ }^{5}$ but less severe, self limiting infection occurs in immunocompetent people. $^{15}$ No effective chemotherapy is available. ${ }^{1}$

We report two cases of human cryptosporidiosis which suggest that person to person transmission took place in hospital.

\section{Case reports}

Case 1-A 13 month old boy was admitted with vomiting, profuse watery diarrhoea, and dehydration which required correction with intravenous fluids. Gastroenteritis was diagnosed and he was nursed in isolation. Initial screening for enteropathogens yielded Escherichia coli 0111 only, which may have contributed to the initial diarrhoea. Jejunal aspirates and blood cultures also yielded Candida; this and the $E$ coli were eliminated by appropriate chemotherapy. Despite temporary alleviation of diarrhoea by loperamide intravenous feeding for 52 days was necessary before a disaccharide free oral feed was tolerated. Diarrhoea (six to eight watery stools a day) recurred 16 days after starting loperamide, and faeces collected 16 days later ( 44 days fter admission) were examined for Cryptosporidium oocysts in smears stained by Giemsa and modified Ziehl-Neelsen methods. ${ }^{4}$ Oocysts were seen in this specimen; earlier samples were not available. They were identical in size morphology staining and centrifugation characteristics with those in faeces from infected calves. Oocysts were seen in further samples taken over the next 25 days. Despite inquiries the source of infection was not traced, but we believe that the patient was infected before admission. Prolonged excretion of oocysts in otherwise normal patients is unusual.

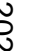

